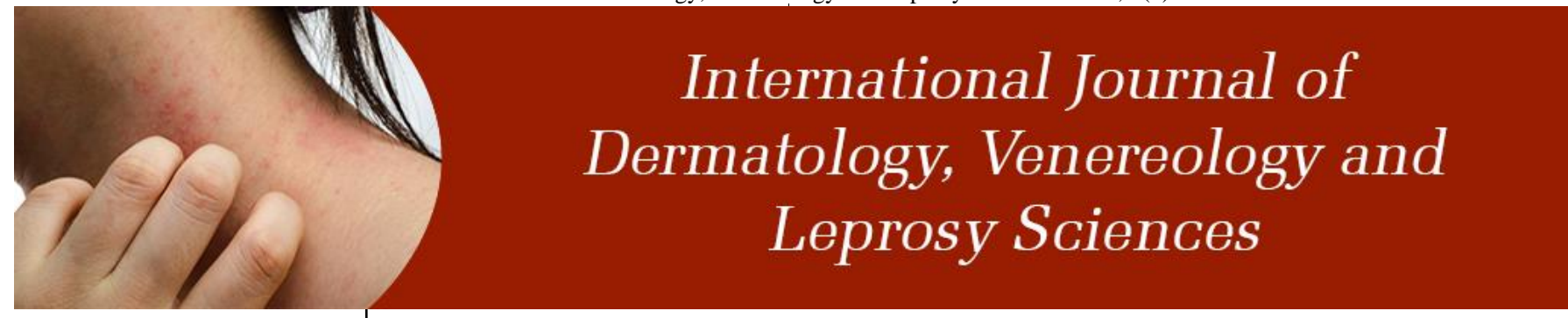

E-ISSN: 2664-942X P-ISSN: 2664-9411 www.dermatologypaper.com Derma 2020; 3(2): 06-08 Received: 04-05-2020 Accepted: 08-06-2020

\section{YS Marfatia}

Professor, Department of Skin \& VD, Dhiraj Hospital, SBKS Medical Institute \& Research Centre, Vadodara, Gujarat, India

Dr. Rashmi Mahajan Professor and Head, Department of Skin \& VD Dhiraj Hospital, SBKS Medical Institute \& Research Centre, Vadodara, Gujarat, India

Dr. Shivaprasad Gouda Department of Skin \& VD Sumandeep Vidyapeeth Deemed to be University, Piparia, Waghodia, Gujarat, India
Corresponding Author: Dr. Rashmi Mahajan Professor and Head, Department of Skin \& VD, Dhiraj Hospital, SBKS Medical Institute \& Research Centre, Vadodara, Gujarat, India

\section{Antisynthetase syndrome: An underdiagnosed entity}

\author{
YS Marfatia, Dr. Rashmi Mahajan and Dr. Shivaprasad Gouda
}

DOI: https://doi.org/10.33545/26649411.2020.v3.i2a.38

\begin{abstract}
Anti-synthetase syndrome is an autoimmune disease, characterized by aminoacyl transfer RNA synthetase antibodies with clinical features that can include interstitial lung disease, myositis, Raynaud's phenomenon, and arthritis. There is a higher prevalence and increased severity of interstitial lung disease in patients with the anti-synthetase syndrome as compared to other inflammatory myopathies. Diagnosis is made by serological, radiographic, and muscle and/or lung biopsy results. Patients frequently require multi-modality immunosuppressive therapy to manage muscular and pulmonary manifestations of the disease. Careful attention is required to the adverse effects and complications of chronic immunosuppressive therapy, as well as to the disease complications which include progressive interstitial lung disease, pulmonary hypertension, and malignancy. Increased awareness of this syndrome will allow for early diagnosis and treatment improving outcomes in patients.
\end{abstract}

Keywords: antisynthetase syndrome, myositis, interstitial lung disease

\section{Introduction}

Antisynthetase syndrome (ASS) was first described by Marguerite and coworkers in $1990^{[1]}$. It is a rare idiopathic autoimmune connective tissue disorder characterized by the presence of autoantibodies against the aminoacyl-tRNA synthetase (antiARS) complex with variable clinical presentation. Typically cases present with a triad of interstitial lung disease (ILD), arthritis, and myositis whereas Raynaud's phenomenon, mechanic's hands, and fever are less prevalent. ASS affects women and men in an approximate ratio of 2: 1 and ages from $22-74$ years ${ }^{[2]}$. Solomon et al. (2011) diagnostic criteria is used to confirm the diagnosis.

\section{Solomon et al. (2011) diagnostic criteria ${ }^{[3]}$}

Required criteria: Presence of anti-aminoacyl tRNA synthetase antibody Plus 2 major or 1 major and 2 minor criteria

Major 1) Interstitial lung disease (not attributable to another cause) 2) Polymyositis or dermatomyositis by Bohan and Peter criteria

Minor -1) Arthritis 2) Raynaud's phenomenon 3) Mechanic's hands

\section{Case report}

A 35-year-old male presented with gradually progressive grade 2 exertional dyspnea and dry cough since 3 years. History of joint pain over bilateral knees, elbows, and wrists with Raynaud's phenomenon affecting fingertips was present since 1.5 years. There was no history of fever, weakness in thighs or shoulder girdle, photosensitivity, oral ulcers or difficulty in swallowing. General physical examination was normal. Cutaneous examination revealed hyperkeratotic, scaly plaques with fissuring over palmar and radial aspect of hands, akin to mechanic s hand (Fig $1 \mathrm{~A}$ and B) mild tapering of the left index finger was seen (Fig 2). Respiratory system examination revealed decreased chest expansion to $3 \mathrm{~cm}$ on palpation and fine bibasilar Velcro crepitations (inspiratory) on auscultation. Musculoskeletal system examination was normal with normal muscle power and a normal range of movements was present. Cardiovascular system examination was normal. His complete blood count, liver function test, renal function test, random Blood Sugar, thyroid-stimulating hormone, $T_{3}, T_{4}$, anti-cyclic citrullinated peptide, phosphokinase levels were within normal limits. Serum VDRL, HIV, HBsAg, and HCV was nonreactive. Electrocardiography, 2D echocardiography, ultrasonography of abdomen and pelvis, X-ray hand (AP view), X-ray 
pelvis (AP view) X-ray bilateral knee joint (AP view) were normal. Chest X-Ray showed patchy consolidation in bilateral lower lobes (fig 3). High-resolution computed tomography (HRCT) showed intra and interlobular septal thickening, mild tubular traction bronchiectasis, and diffuse ground-glass opacity in both lower lobes, suggestive of nonspecific interstitial pneumonia (fig 4). Serum anti-nuclear antibodies (ANA) profile was positive for antiJO-1 (+++) and antiRO-52(+++). Diagnosis of ASS was confirmed on basis of presence of required criteria (AntiJO1 antibody) along with one major criteria (ILD) and three minor criteria (Raynauds phenomenon, mechanics hand, arthritis). The patient was prescribed azathioprine $50 \mathrm{mg}$ orally once a day and supportive therapy for 6 months. As there was little clinical improvement, he was given intravenous cyclophosphamide pulse therapy, $500 \mathrm{mg}$ every 4 weeks with regular monitoring. He was maintained on oral prednisolone $0.5 \mathrm{mg} / \mathrm{kg}$ daily, multivitamins, calcium $500 \mathrm{mg}+$ vitamin $\mathrm{D}_{3} 250 \mathrm{IU}$, metered dose inhaler levosalbutamol/levalbuterol $50 \mathrm{mcg}+$ ipratropium $40 \mathrm{mcg}$, emollients and topical clobetasol $(0.05 \%)+$ salicylic acid cream (3\%). Significant improvement was observed in cutaneous lesions and joint pain however there was no improvement in dyspnea.

\section{Discussion}

ASS is an idiopathic inflammatory myopathy (IIM). Associated signs and symptoms include ILD, myositis, arthritis, Raynaud's phenomenon, fever and mechanic's hand (Fig 5). A higher prevalence of ILD is seen in ASS relative to other inflammatory myopathies ${ }^{[3]}$. Incomplete forms, especially initial symptoms may not suggest ASS. ASS can also present with isolated manifestations of either ILD, arthritis, or myositis ${ }^{[4]}$. Our patient presented with ILD without myositis and fever. In atypical cases inflammatory arthritis may mimic RA. In cases of oesophageal involvement or pulmonary hypertension, overlapping systemic sclerosis should be considered. Several antinuclear antibodies such as anti JO-1, anti-PL-7, anti-PL-12, anti-OJ, anti-EJ, anti-ZO, anti-YRS/Ha and anti-KS are seen. Presence of one or more of the above antibodies is a "required criteria for diagnosis of ASS" (Table-1). Other myositis specific autoantibodies may also be seen in ASS (Fig6)

Management of ASS includes systemic corticosteroids $1 \mathrm{mg} / \mathrm{kg} /$ day as the first-line therapy. Some ASS patients may have corticosteroid resistant myositis or ILD. Azathioprine $1 \mathrm{mg} / \mathrm{kg} /$ day is a second-line agent. IVIG or MMF (mycophenolate mofetil) can also be used as add on therapy. In acute exacerbations cyclophosphamide $500 \mathrm{mg}$
IV every 4 weeks or Rituximab $1 \mathrm{~g}$ with an interval of 2 weeks can be used as rescue therapy ${ }^{[9]}$.

The ILD in ASS cases is often severe and rapidly progressive, causing increased morbidity and mortality as compared with other IIMs. Patients with pulmonary hypertension and age greater the 60 years have poor prognostic factors. The most common causes of death are pulmonary fibrosis and pulmonary hypertension. Hence severe and aggressive ILD require multi-modality therapy and lung transplantation is to be considered when the disease is progressive and fails to respond to treatment ${ }^{[8]}$.
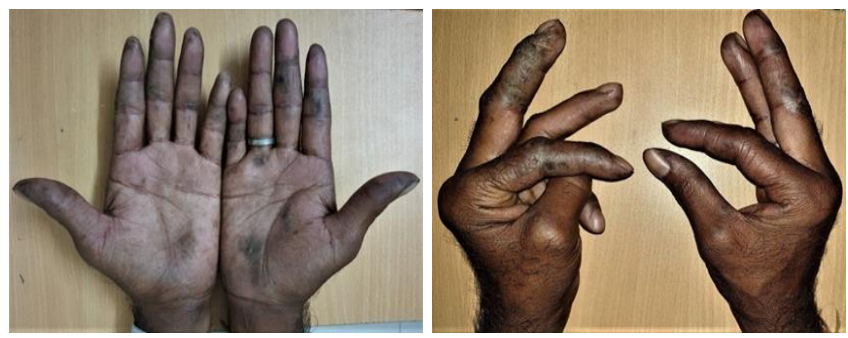

Fig 1(A, B): Mechanic's hand.

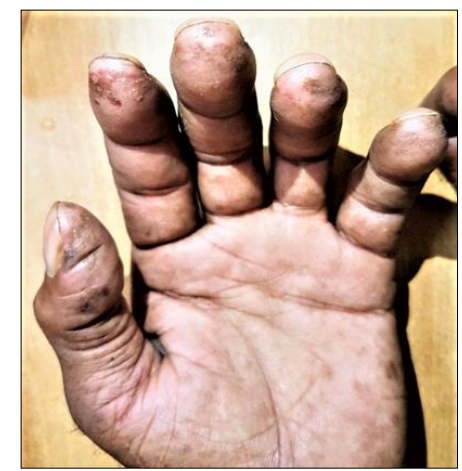

Fig 2: Tapering of the left index finger with mechanic's hand.

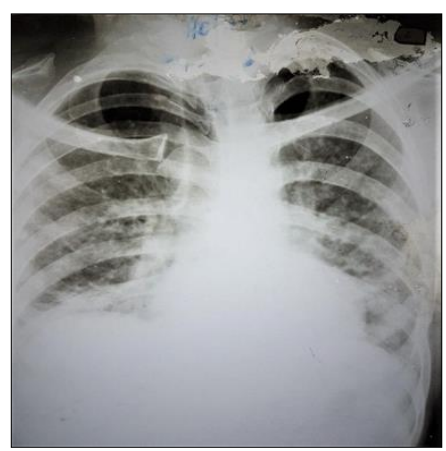

Fig 3: Chest X-Ray anteroposterior view showing patchy consolidation in bilateral lower lobes.
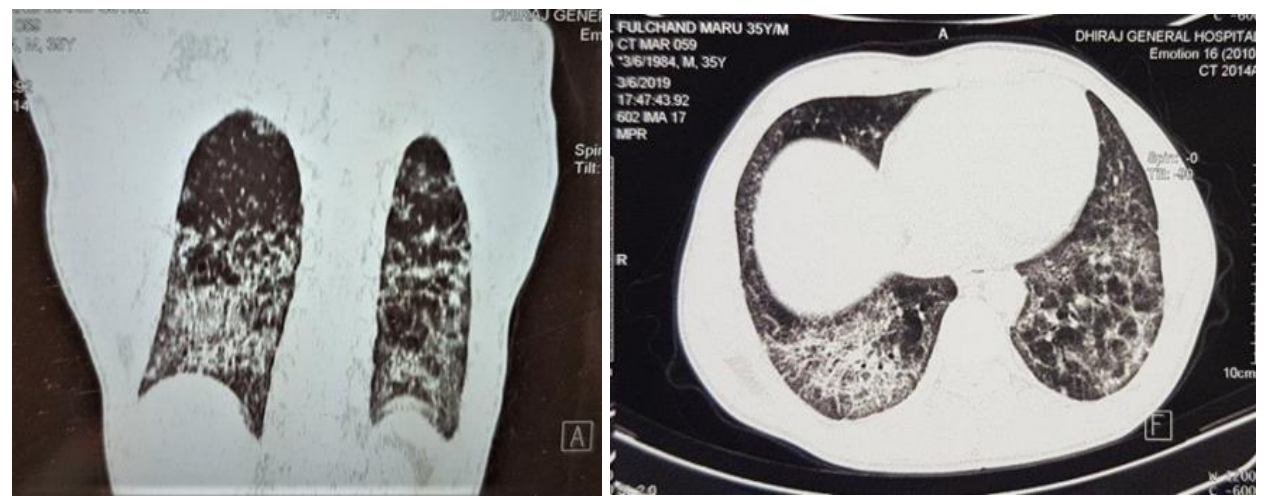

Fig 4(A, B): HRCT chest showing diffuse ground-glass opacity in both lower lobes, suggestive of nonspecific interstitial pneumonia. 


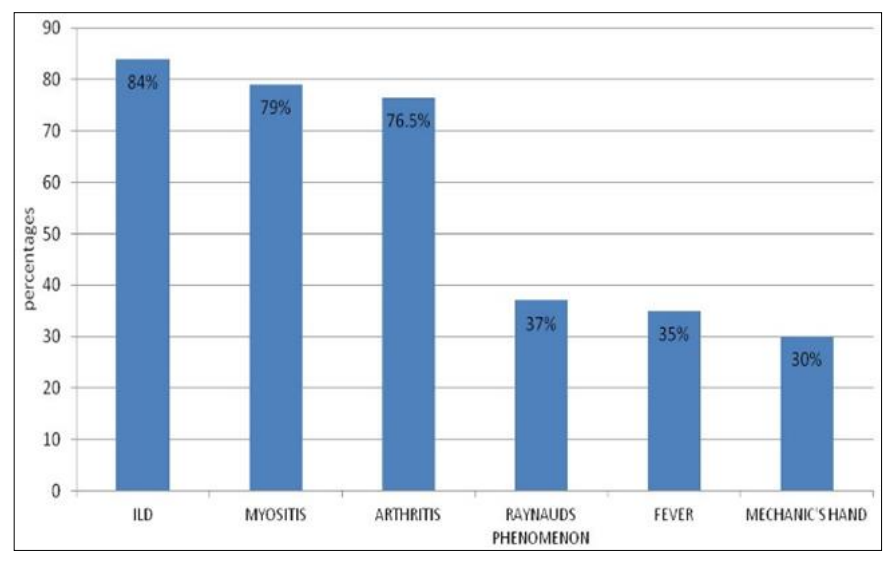

Fig 5: Prevalence of signs and symptoms according to the cohort study conducted by the American, European Network of Antisynthetase Syndrome (AENEAS) collaboration group Cavagna L, Nuño L, Scirè CA et al. ${ }^{[4]}$.

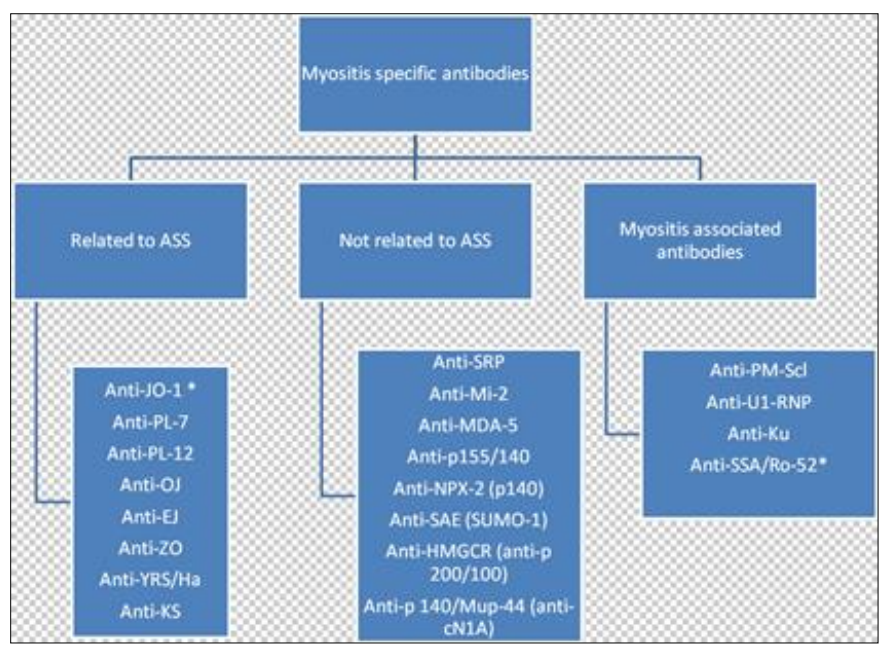

Fig 6: Myositis-specific antibodies ${ }^{[5]}$.

Table 1: Presence of one or more of the above antibodies is a required criteria for diagnosis of ASS

\begin{tabular}{|c|c|c|}
\hline \begin{tabular}{|c|} 
Myositis-specific \\
antibodies related to ASS
\end{tabular} & Target antigen & Significance \\
\hline Anti-JO-1 & $\begin{array}{l}\text { histidyl t- RNA } \\
\text { synthetase }\end{array}$ & $\begin{array}{l}\text { The most common antisynthetase antibody, Develops as the classical form. Strong predictor } \\
\text { for ILD }(70-90 \%) \text {, but also a strong predictor of clinical response to immunobiological drug }\end{array}$ \\
\hline Anti-PL-7 & $\begin{array}{c}\text { threonyl t- RNA } \\
\text { synthetase }\end{array}$ & $\begin{array}{l}\text { Increased involvement of the gastrointestinal tract, Raynaud's phenomenon, and ILD. } \\
\text { Isolated ILD is typical, but milder compared to anti-PL-12. This happens in myositis as well }\end{array}$ \\
\hline Anti-PL-12 & $\begin{array}{l}\text { alanyl t- RNA } \\
\text { synthetase }\end{array}$ & \begin{tabular}{|c|} 
Increased involvement of the gastrointestinal tract, Raynaud's phenomenon, and ILD. ILD \\
isolated is typical but has a greater burden of ILD and esophageal involvement and a lower \\
chance of developing arthritis and myositis compared to anti-PL-7
\end{tabular} \\
\hline Anti-OJ & $\begin{array}{c}\begin{array}{c}\text { isoleucyl t- RNA } \\
\text { synthetase }\end{array} \\
\end{array}$ & $\begin{array}{l}\text { ILD is common but responds very well to glucocorticosteroids. Strong association with } \\
\text { neoplasia, but without statistical evidence }\end{array}$ \\
\hline Anti-EJ & $\begin{array}{c}\text { glycyl t- RNA } \\
\text { synthetase }\end{array}$ & $\begin{array}{l}\text { It develops the classic form with myopathy and ILD and is possibly the one with the lowest } \\
\text { association with malignancy }\end{array}$ \\
\hline Anti-KS & $\begin{array}{c}\text { asparaginyl } \\
\mathrm{t}-\mathrm{RNA} \text { synthetase } \\
\end{array}$ & DPI is frequent, but Raynaud's phenomenon and arthritis are not. Myositis was not evidenced \\
\hline Anti-ZO & $\begin{array}{c}\text { phenylalanyl } \\
\mathrm{t}-\text { RNA synthetase }\end{array}$ & $<1 \%$ in ASS, Develops as the classical form. \\
\hline \begin{tabular}{|c|}
$\begin{array}{c}\text { Anti-YRS or Anti-TyR or } \\
\text { anti-Ha }\end{array}$ \\
\end{tabular} & $\begin{array}{c}\text { tyrosyl t- RNA } \\
\text { synthetase }\end{array}$ & $<1 \%$ in ASS, Develops as the classical form. \\
\hline
\end{tabular}

\section{Conclusion}

Antisynthetase syndrome is a lesser known but important and treatable cause of ILD. Unexplained acute respiratory distress syndrome, Raynaud's phenomenon, and mechanic's hands should raise the suspicion of anti-synthetase syndrome for appropriate management to reduce morbidity and mortality of patient.

\section{References}

1. Marguerie C, Bunn C, Beynon $\mathrm{H}$ et al. Polymyositis, pulmonary fibrosis and autoantibodies to aminoacyltRNA synthetase enzymes. QJM. 1990; 77:1019-1038.

2. Mirrakhimov AE. Antisynthetase syndrome: A review of etiopathogenesis, diagnosis and management. Curr Med Chem. 2015; 22(16):1963-75.

3. Solomon J, Swigris JJ, Brown KK. Myositis-related interstitial lung disease and antisynthetase syndrome. Jornal Brasileiro de Pneumologia. 2011; 37:100-109.

4. Cavagna L, Nuño L, Scirè CA et al., AENEAS (American, European Network of Antisynthetase Syndrome) collaborative group: Clinical spectrum time course in anti Jo-1 positive antisynthetase syndrome: Results from an international retrospective multicenter study. Medicine (Baltimore). 2015; 94(32):e1144.

5. Sibilia J, Chatelus E, Meyer A et al. Comment faire le diagnostic et mieux comprendre les myopathies inflammatoires? L'utilité des auto-anticorps. Presse Med, Elsevier. 2010; 39:1010-25 [in French]

6. Rojas-Serrano J, Herrera-Bringas D, Mejía M et al. Prognostic factors in a cohort of antisynthetase syndrome (ASS): Serologic profile is associated with mortality in patients with interstitial lung disease (ILD). Clin Rheumatol. 2015; 34:1563-69.

7. Hervier B, Devilliers H, Stanciu R et al. Hierarchical cluster and survival analyses of antisynthetase syndrome: Phenotype and outcome are correlated with anti-tRNA synthetase antibody specificity. Autoimmun Rev. 2012; (12):210-17.

8. Shi J, Li S, Yang $\mathrm{H}$ et al. Clinical profiles and prognosis of patients with distinct antisynthetase autoantibodies. J Rheumatol. 2017; 47(7):1051-57.

9. Witt LJ, Curran JJ, Strek ME. The Diagnosis and Treatment of Antisynthetase Syndrome. Clin Pulm Med. 2016; 23(5):218-226. 